\title{
Metabolic and Lactational Responses during Recombinant Bovine Tumor Necrosis Factor- $\alpha$ Treatment in Lactating Cows
}

\author{
S. Kushibiki, ${ }^{*}$ K. Hodate, $†$ H. Shingu, ${ }^{*}$ Y. Obara, $\ddagger$ E. Touno, ${ }^{*}$ M. Shinoda, ${ }^{\star}$ and Y. Yokomizo§ \\ *Department of Animal Production, \\ National Agricultural Research Organization, \\ National Agricultural Research Center for Tohoku Region, \\ Iwate-ken 020-0198, Japan \\ †School of Veterinary Medicine and Animal Sciences, \\ Kitasato University, \\ Aomori-ken 034-8628, Japan \\ $\ddagger$ Department of Science of Biology Function, \\ Tohoku University, \\ Miyagi-ken, 981-0914, Japan \\ $\S$ Department of Animal Immunology, \\ National Agricultural Research Organization, \\ National Institute of Animal Health, \\ Ibaraki-ken 305-0856, Japan
}

\begin{abstract}
This study examined the effects of recombinant bovine tumor necrosis factor- $\alpha$ (rbTNF) administration on metabolic and hormonal responses and lactational performance in dairy cows. Twelve lactating Holstein cows were injected subcutaneously with $\mathrm{rbTNF}(2.5 \mu \mathrm{g}$ per kg per d) or saline ( $3 \mathrm{ml}$ per head per d) at $1200 \mathrm{~h}$ daily for $7 \mathrm{~d}(\mathrm{~d} 0-6)$ and used in a crossover design. The rbTNF treatment induced increases in plasma haptoglobin, nonesterified fatty acid, cortisol, and growth hormone levels compared with the control levels. The rbTNF-treated cows had lower triiodothyronine and insulin-like growth factor-1 concentrations than control cows. In a somatoliberin challenge on $d 6$, the somatotropin response to somatoliberin $(0.25 \mu \mathrm{g} / \mathrm{kg})$ was smaller in the rbTNF group than in the control. The rbTNF treatment also produced increases of the nitrite plus nitrate concentration in plasma and milk during the period between $\mathrm{d} 1$ and 7 . Milk yield was reduced by rbTNF administration from $d 1$ to 8 . The percentage of milk fat was increased on d $1-7$ by rbTNF treatment, but milk protein content in the rbTNF group was decreased on $\mathrm{d} 5$ and 7 as compared with that in the control group. These results support the possibility that tumor necrosis factor- $\alpha$ is responsible for the changes in hormone secretion, milk production and composition, and inflammatory parameters observed during coliform mastitis.
\end{abstract}

Received May 14, 2002.

Accepted August 15, 2002.

Corresponding author: Shiro Kushibiki; e-mail: mendoza@ affrc.go.jp.
(Key words: recombinant bovine tumor necrosis factor- $\alpha$, metabolite, hormone, mastitis)

Abbreviation key: APR = acute phase response, $\mathbf{H P}$ = haptoglobin, IGF-1 = insulin-like growth factor 1, LPS = lipopolysaccharide, NEFA = nonesterified fatty acid, $\mathbf{N O}=$ nitric oxide, $\mathbf{N O}_{\mathbf{x}}=$ nitrite plus nitrate, rbTNF $=$ recombinant bovine tumor necrosis factor- $\alpha$, ST = somatotropin, $\mathbf{S T R H}=$ somatoliberin, $\mathbf{T N F}=$ tumor necrosis factor $-\alpha, \mathbf{T}_{\mathbf{3}}=$ triiodothyronine.

\section{INTRODUCTION}

Mastitis is recognized as one of the most important diseases affecting dairy cows worldwide (Hill et al., 1979). It can be caused by a large number of bacterial species, and in particular, Escherichia coli-induced mastitis with severe clinical symptoms is most frequently observed during early lactation (Hill et al., 1979). Coliform mastitis has adverse effects on the economics of milk production by reducing the quantity and quality of milk (Shuster et al., 1991c).

Bacterial lipopolysaccharide (LPS), often called endotoxin, is considered to be the key molecule in the development of coliform mastitis (Shuster et al., 1991a). Indeed, intramammary infusion of LPS in dairy cows induces clinical (fever, tachycardia), metabolic (a decrease in plasma $\mathrm{Zn}$ and Fe concentrations), and hematologic (neutropenia followed by neutrophilia) disturbances, which are a set of responses generally referred to as the acute phase response (APR) (Lohuis et al., 1992). In these cows, milk yields are depressed in quarters not receiving LPS despite the absence of inflammation in the quarters (Shuster et al., 1991a). Thus, the suppression in milk production is apparently medi- 
ated by systemic effects of intramammary LPS infusion. Intravenous administration of LPS induces many of the systemic responses associated with mastitis, including increases in rectal temperature and serum cortisol (Jackson et al., 1990). On the other hand, there are various indications that LPS is not released from the mammary gland into the general circulation (Dosogne et al., 2002; Hirvonen et al., 1999), but proinflammatory cytokines [e.g. tumor necrosis factor- $\alpha$ (TNF)], Interleukin-1 $\beta$, Interleukin-6) produced during APR enter the circulation and cause the systemic effects (Hoeben et al., 2000).

A recent study suggested that TNF plays a vital role in the pathophysiology associated with coliform mastitis and/or APR (Hoeben et al., 2000). Bovine mammary macrophages secrete TNF in response to LPS (Pighetti and Sordillo, 1994), and the serum TNF level increases in coliform mastitis (Hoeben et al., 2000). In fact, the administration of recombinant bovine tumor necrosis factor- $\alpha$ (rbTNF) to calves induced shock and metabolic and hormonal changes in plasma similar to those observed after LPS administration (Kushibiki et al., 2000a). The studies using LPS have been done with lactating cows (Shuster et al., 1991b), but the effects of exogenous TNF treatment on hormonal response, lactational performance and mastitic parameters have not yet been studied. Moreover, little information has been reported on somatotropin (ST), insulin-like growth factor 1 (IGF-1) and thyroid hormone responses to TNF treatment of lactating cows, although these hormones are important regulators of mammary gland function.

The objective of the present study using lactating cows was to investigate some metabolic and hormonal changes and lactational performance during rbTNFinduced APR in order to provide evidence that TNF is an in vivo mediator of coliform mastitis-stimulated systemic changes.

\section{MATERIALS AND METHODS}

\section{Cows and Feeding}

Twelve nonpregnant, lactating Holstein cows (average $\mathrm{BW} \pm \mathrm{SE}, 584.6 \pm 17.1 \mathrm{~kg}$ ) of 1 st to $3 \mathrm{rd}$ parity between 10 and 14 wk after parturition were used in this study. They were housed in tie stalls with $12 \mathrm{~h}$ of light/d and were milked twice daily at 0600 and 1600 $\mathrm{h}$ with a quarter milking machine, and the daily milk yield was recorded. The cows were fed according to Japanese Feeding Standard (1994) recommendations for dairy cows yielding $30 \mathrm{~kg} / \mathrm{d}$ of milk containing $3.5 \%$ fat at 0900 and $1700 \mathrm{~h}$ daily. The diet consisted of $41.4 \%$ mixed concentrate, $22.0 \%$ corn silage, $12.6 \%$ alfalfa hay cube, and $24.0 \%$ orchardgrass hay (DM basis). Water and mineral blocks were continuously available. Dry matter intake was recorded for each cow from $3 \mathrm{~d}$ prior to the treatment period ( $\mathrm{d} 0-6)$ until $3 \mathrm{~d}$ after the challenge. The cows were cared for according to TNAES (1998) based on Consortium (1988).

\section{Experimental Protocol}

Twelve Holstein cows were randomly divided into a rbTNF treatment group $(\mathrm{n}=6)$ and a saline treatment group $(\mathrm{n}=6)$ as a control. The rbTNF $(2.5 \mu \mathrm{g}$ per $\mathrm{kg}$ $\mathrm{BW}$ per d) or saline ( $3 \mathrm{ml}$ per head per d) was injected s.c. at $1200 \mathrm{~h}$ daily for 7 consecutive $\mathrm{d}(\mathrm{d} 0-6)$. The dose of rbTNF was adjusted according to the BW determined at the beginning of treatment ( $\mathrm{d} 0$ ). The cows were used in a crossover design. The experimental period included a rest period of 3 wks to avoid carryover effects. Highly purified rbTNF was provided by Higeta Shoyu Co., Ltd. (Choshi, Japan). The method of producing this cytokine was described previously (Kushibiki et al., 2000b). Blood samples (4 ml) were collected from the external jugular vein into sodium heparin-containing tubes (Terumo Co., Ltd., Tokyo) at $1130 \mathrm{~h}$ daily during the experimental period, and were stored on ice and centrifuged $(25 \mathrm{~min}$ at $1000 \times \mathrm{g})$ at $4^{\circ} \mathrm{C}$. Plasma was aspirated and stored at $-20^{\circ} \mathrm{C}$ until analyzed for metabolites and hormones. Milk samples from cows were collected twice daily for composition analysis. The milk samples were collected on d $0,1,3,5$, and 7 . The milk samples consisted of mixtures of evening milk and next-morning milk, and a portion of each sample was stored at $-20^{\circ} \mathrm{C}$. The rest of the sample was used to prepare skim milk by centrifugation at $1000 \times \mathrm{g}$ and $4^{\circ} \mathrm{C}$ for $15 \mathrm{~min}$. After the fat layer was discarded, the skim milk was stored at $-20^{\circ} \mathrm{C}$ until analysis for nitrite plus nitrate $\left(\mathbf{N O}_{\mathbf{x}}\right)$.

On $\mathrm{d} 6$ in the experimental period, we determined the effect of daily administration of rbTNF on somatoliberin (NIAIST) (STRH)-stimulated somatotropin (ST) release (STRH challenge, $0.25 \mu \mathrm{g} / \mathrm{kg} \mathrm{BW}$ ). On the challenge day, a catheter was inserted into the left external jugular vein at $1000 \mathrm{~h}$, and was maintained by flushing of heparinized saline solution. The STRH was dissolved in saline at $25.0 \mu \mathrm{g} / \mathrm{ml}$. The preparation was injected via the catheter immediately following the rbTNF or saline treatment at $1200 \mathrm{~h}$. Blood samples $(4 \mathrm{ml})$ were collected through the catheter into tubes containing sodium heparin at $-15,0$ (just before injection), 5,10 , $15,20,30,45,60,90,120 \mathrm{~min}$ after the injection. The samples were kept on ice after collection and centrifuged $(25 \mathrm{~min}$ at $1000 \times \mathrm{g})$ at $4^{\circ} \mathrm{C}$. The plasma was harvested and stored at $-20^{\circ} \mathrm{C}$ until analyzed for ST. 


\section{Analysis of Blood and Milk Components}

The concentration of plasma haptoglobin (HP) was determined by a single-immunodiffusion method using a kit (Saikin Kagaku, Sendai, Japan) specific for bovine HP, as described previously (Morimatsu et al., 1992). The limit of detection was $25 \mu \mathrm{g} / \mathrm{ml}$ for HP. Plasma nonesterified fatty acid (NEFA) was measured with a commercially available kit (Wako Pure Chemical Industries, Osaka) using a Hitachi 7070 autoanalyzer (Hitachi Ltd., Tokyo). Cortisol in plasma was determined with a RIA kit from Eiken Chemical (Tokyo). This kit contains a bovine cortisol standard. The plasma concentration of triiodothyronine $\left(\mathbf{T}_{\mathbf{3}}\right)$ was determined using a RIA kit (Eiken Chemical, Tokyo) previously validated for use in cattle (Rumsey et al., 1990). ST analysis was performed using RIA for bovine ST as described by Johke (1978). Intra- and interassay coefficients of variation were 4.8 and $6.3 \%$ for cortisol, 5.2 and $7.7 \%$ for $\mathrm{T}_{3}$, and 5.5 and $8.7 \%$ for ST, respectively. The plasma concentration of IGF-1 in daily samples of each treatment group was determined using a double antibody RIA (Hodate et al., 1990). The intraassay coefficient of variation was $5.1 \%$ for IGF-1.

Nitric oxide (NO) production was evaluated by measuring its more stable metabolite, NOx. The concentrations of $\mathrm{NO}_{\mathrm{x}}$ in plasma and milk were the sum of the nitrite $\left(\mathrm{NO}_{2}\right)$ and nitrate $\left(\mathrm{NO}_{3}\right)$ levels. Immediately prior to the determination of $\mathrm{NO}_{\mathrm{x}}$ in milk, the skim milk samples were centrifuged twice for $15 \mathrm{~min}$ at $10,000 \times$ $\mathrm{g}$ at $4^{\circ} \mathrm{C}$, and the whey fraction between the supernatant (fat layer) and the infranatant (precipitates) was removed. To measure $\mathrm{NO}_{\mathrm{x}}, \mathrm{NO}_{3}$ was converted to $\mathrm{NO}_{2}$ by the addition of $\mathrm{NO}_{3}$ reductase, and $\mathrm{NO}_{2}$ was then measured at $540 \mathrm{~nm}$ by the Griess reaction (Blum et al., 2000).

Milk fat and protein were measured with an infrared milk analyzer.

\section{Statistical Analysis}

Data were analyzed using a repeated measurement design with the GLM procedure of SAS (1988). The model was $\mathrm{Y}_{\mathrm{ijk}}=\mu+\mathrm{A}_{\mathrm{i}}+\mathrm{B}_{\mathrm{j}}+\mathrm{C}_{\mathrm{k}}+(\mathrm{AC})_{\mathrm{ik}}+\mathrm{e}_{\mathrm{ijk}}$, where $\mathrm{Y}_{\mathrm{ijk}}=$ observed value, $\mu=$ overall mean, $\mathrm{A}_{\mathrm{i}}=$ effect of treatment, $B_{j}=$ effect of individual cows, $C_{k}=$ effect of sampling day or time, $(\mathrm{AC})_{\mathrm{ik}}=$ interaction of treatment and sampling day or time, and $\mathrm{e}_{\mathrm{ijk}}=$ random residual error.

All data are presented as mean $\pm \mathrm{SE}$ and $P<0.05$ was considered significant.

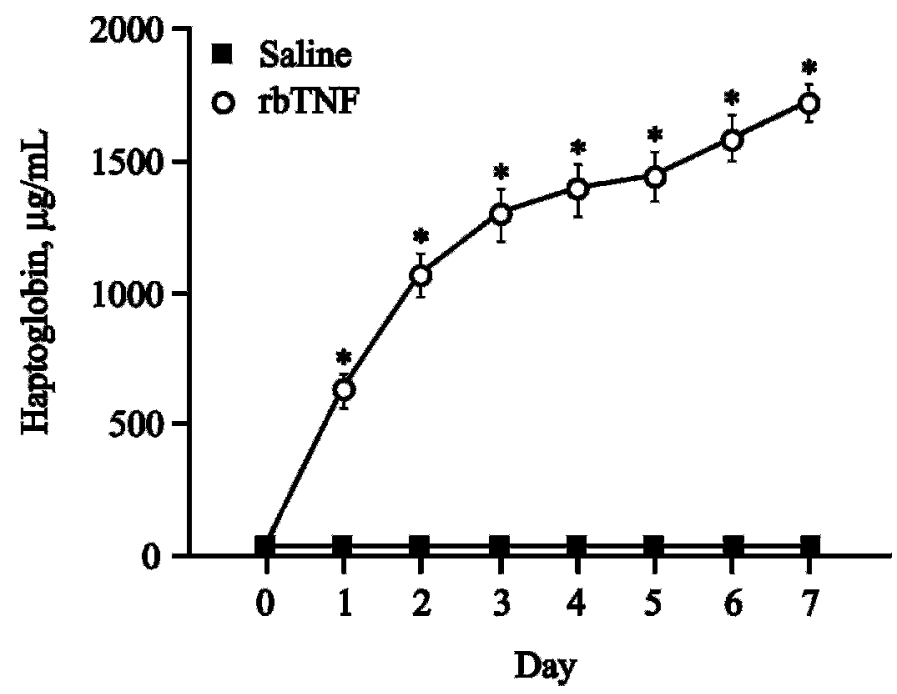

Figure 1. Plasma concentrations of haptoglobin (HP) in cows given s.c. injections of saline (control, $3 \mathrm{~mL} / \mathrm{head}$ ) or recombinant bovine tumor necrosis factor-alpha ( $\mathrm{rbTNF}, 2.5 \mu \mathrm{g} / \mathrm{kg}$ ) once daily for $7 \mathrm{~d}$. Blood samples were collected from the jugular vein at $1130 \mathrm{~h}$ daily during the period from d 0 until 7 . The saline or rbTNF was administered at $1200 \mathrm{~h}$ daily for $7 \mathrm{~d}(\mathrm{~d} 0-6)$. Each point represents the mean $\pm \mathrm{SE} ; 12$ cows per treatment. ${ }^{*} P<0.05$ compared to control.

\section{RESULTS}

\section{Feed Intake, Blood Metabolites and Hormones}

The rbTNF treatment produced some local inflammatory reaction (heat, swelling) around the place of s.c. injection during the period between $\mathrm{d} 1$ and 9 .

During the treatment $(\mathrm{d} 0-6)$ and posttreatment $(\mathrm{d}$ 7 -9) periods, DM intake for cows treated with rbTNF was depressed $(P<0.05) 34.3$ and $20.0 \%$ when compared to control cows (data not shown).

The concentration of HP in the cows treated with rbTNF was already elevated $(P<0.05)$ at $d 1$ and remained significantly higher than that in the control cows throughout the experimental period (Figure 1).

Daily rbTNF administration increased the mean NEFA concentration $(P<0.05)$ from d 3 to 7 compared with the level in control cows (Figure 2).

In the cows treated with rbTNF, the plasma concentration of cortisol was increased during the period between $\mathrm{d} 2$ and 7 compared with that in the control cows (Figure 3, upper panel). The plasma $\mathrm{T}_{3}$ concentration in the rbTNF-injected cows was decreased $(P<0.05)$ at $d 1$ and remained low throughout the experimental period (Figure 3, lower panel).

In the rbTNF group, the plasma concentration of ST was increased throughout the experimental period compared with that of the control group (Figure 4, upper panel). On $d 2-7$, there was a significant difference 


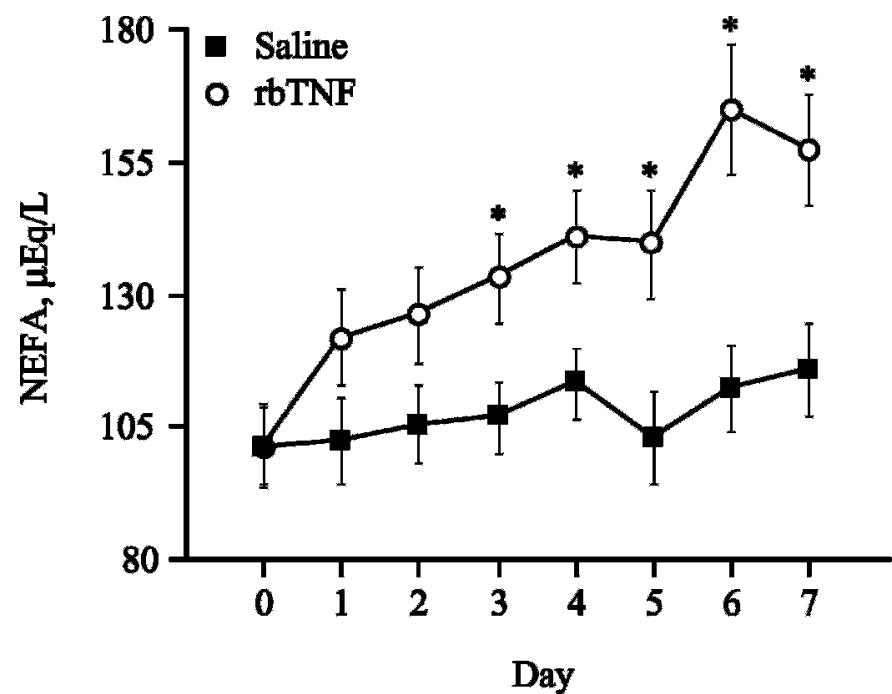

Figure 2. Plasma concentrations of NEFA in cows given s.c. injections of saline (control, $3 \mathrm{~mL} / \mathrm{head}$ ) or $\mathrm{rbTNF}(2.5 \mu \mathrm{g} / \mathrm{kg})$ once daily for $7 \mathrm{~d}$. See Figure 1 for key.

$(P<.05)$ between the plasma concentrations of ST in the rbTNF and control groups.

The concentration of plasma IGF-1 in the cows treated with rbTNF tended to be reduced at $\mathrm{d} 1$ and was significantly lower $(P<.05)$ than in the control cows throughout the period from d 3 to 7 (Figure 4, lower panel).

\section{STRH Challenge}

The ST concentrations in both groups were elevated at 5 min after the STRH administration, but plasma ST was significantly lower $(P<0.05)$ in the rbTNFtreated cows than in the control cows from 15 to 120 min after the STRH administration (Figure 5).

\section{Concentrations of $\mathrm{NO}_{\mathrm{x}}$ in Plasma and Milk}

Plasma $\mathrm{NO}_{\mathrm{x}}$ concentration in the cows treated with rbTNF was increased $(P<0.05)$ at $1 \mathrm{~d}$ and remained elevated level until $7 \mathrm{~d}$ compared with that for the cows treated with saline (Figure 6, upper panel). Similarly, milk $\mathrm{NO}_{\mathrm{x}}$ concentration in the rbTNF-injected cows was higher $(P<0.05)$ than that for the control cows during from 1 to $7 \mathrm{~d}$ (Figure 6, lower panel).

\section{Milk Yields and Compositions}

Treatment with rbTNF decreased the milk yield ( $P$ $<0.05$ ) during the period between $\mathrm{d} 1$ and 8 (Figure 7). The milk fat percentage was elevated $(P<0.05)$ at $\mathrm{d} 1$ following rbTNF treatment and remained higher until
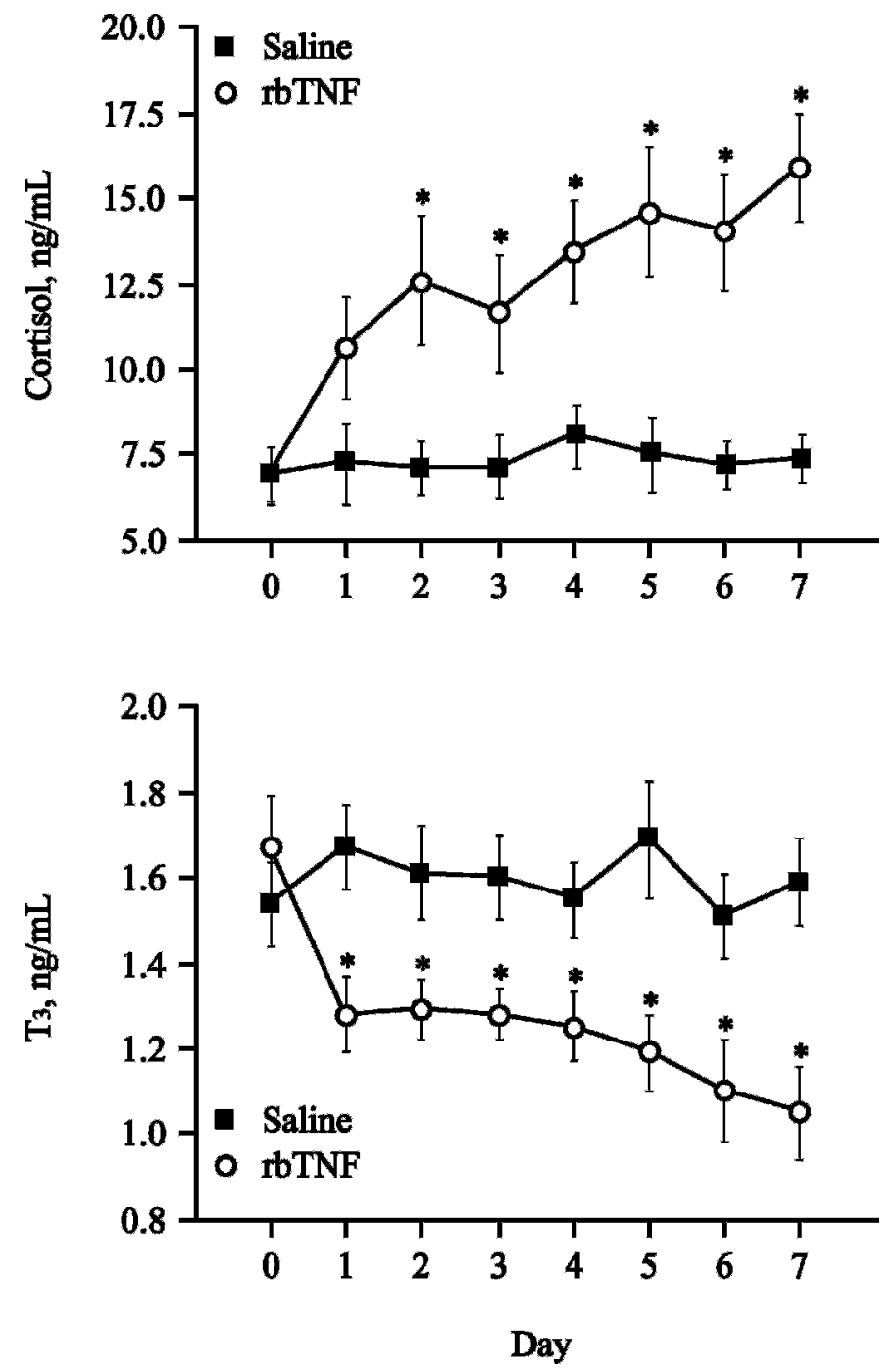

Figure 3. Plasma concentrations of cortisol (upper panel) and triiodothyronine ( $\mathrm{T}_{3}$, lower panel) in cows given s.c. injections of saline (control, $3 \mathrm{~mL} / \mathrm{head}$ ) or $\mathrm{rbTNF}(2.5 \mu \mathrm{g} / \mathrm{kg})$ once daily for $7 \mathrm{~d}$. See Figure 1 for key.

d 7 in comparison with that in the saline-treated cows (Figure 8, upper panel). The protein content in milk was lower $(P<0.05)$ in the rbTNF-treated cows than in the control cows from $\mathrm{d} 5$ to 7 (Figure 8, lower panel).

\section{DISCUSSION}

Daily treatment with rbTNF induced increases in plasma HP and NEFA levels, and altered hormone concentrations in lactating cows. In addition, rbTNF administration caused an elevation of the $\mathrm{NO}_{\mathrm{x}}$ level in plasma and milk, and influenced lactational performance.

$\mathrm{HP}$ is produced mainly in the liver in response to stimulation by proinflammatory cytokines such as TNF, 

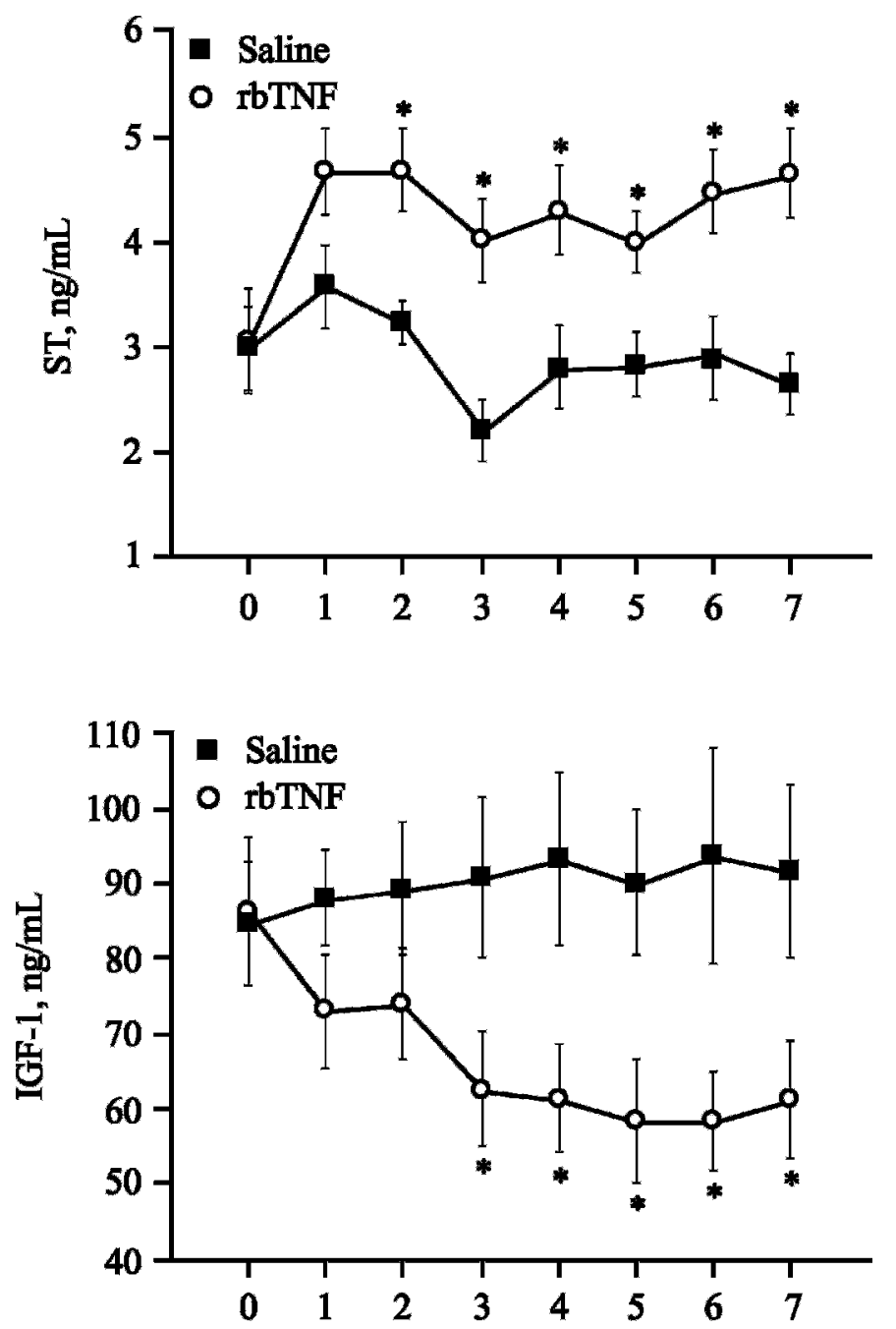

Day

Figure 4. Plasma concentrations of ST (upper panel) and IGF-1 (lower panel) in cows given s.c. injections of saline (control, $3 \mathrm{~mL} /$ head) or rbTNF $(2.5 \mu \mathrm{g} / \mathrm{kg})$ once daily for $7 \mathrm{~d}$. See Figure 1 for key.

which are produced primarily by macrophages and monocytes (Baumann and Gauldie, 1994). This acute phase protein fulfills a number of nonspecific defense functions during the APR (Baumann and Gauldie, 1994). In cattle, plasma HP is a major contributor to the APR (Alsemgeest et al., 1994). We previously demonstrated that a single injection of rbTNF in calves resulted in a dose-dependent increase of the plasma HP level (Kushibiki et al., 2000a).

It has been reported that TNF is responsible for the hyperlipidemia that occurs in association with inflammation or infection (Feingold and Grunfeld, 1987). In mice (Green et al., 1994), TNF causes a delipidation of fat cells and a decrease of the adipose tissue mass.

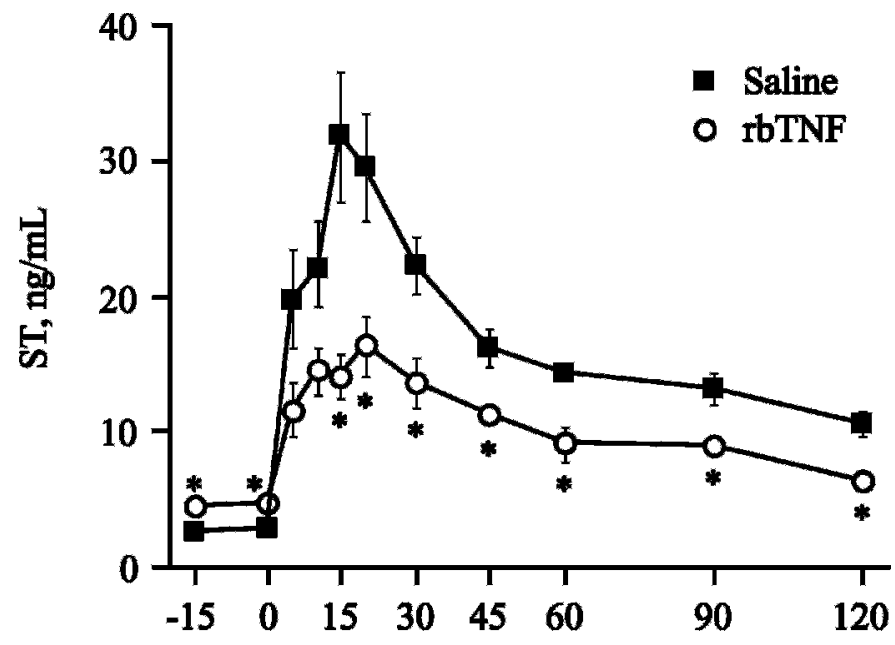

Time after injection, min

Figure 5. Time course of the level of plasma ST after an i.v. injection of STRH $(0.25 \mu \mathrm{g} / \mathrm{kg})$ on d 6 in cows treated with saline (control) or rbTNF. The treatments consisted of $\mathrm{rbTNF}(2.5 \mu \mathrm{g} / \mathrm{kg} / \mathrm{d}$ s.c.) and saline ( $3 \mathrm{~mL} / \mathrm{d}$ s.c.) given by daily injection for $7 \mathrm{~d}(\mathrm{~d} 0-6)$. $* P<0.05$ compared to control.

Hepatic lipid synthesis is also stimulated by TNF administration (Feingold and Grunfeld, 1987). Previously, we demonstrated that a single i.v. administration of rbTNF to heifers resulted in an increase in the plasma NEFA concentration (Kushibiki et al., 2000b). The increased NEFA level observed here in the lactating cows treated with rbTNF was similar to that observed previously in vivo studies. Moreover, when lactating cows are in negative energy balance, lipid reserves are mobilized and oxidation of NEFA is increased, thereby preserving the limited supplies of other key nutrients such as glucose and amino acids (Peel and Bauman, 1987). In the present study, it is possible that the reduction in DM intake during rbTNF treatment resulted in an increase in the circulating NEFA concentration that was highly correlated with energy balance in the lactating cows.

Intramammary or i.v. administration of endotoxin to lactating cows induces many systemic responses associated with mastitis, including an increase in the plasma cortisol level (Jackson et al., 1990). This response results from an endotoxin-induced release of cytokines, e.g., TNF, from peripheral blood monocytes and liver Kupffer cells (Lohuis et al., 1988a). TNF stimulates the hypothalamic-pituitary-adrenal axis in rats, mainly through an effect on the hypothalamus (Bernardini et al., 1990). In the present study, exogenous rbTNF treatment elicited a pronounced elevation of the plasma cortisol concentration in lactating cows. 

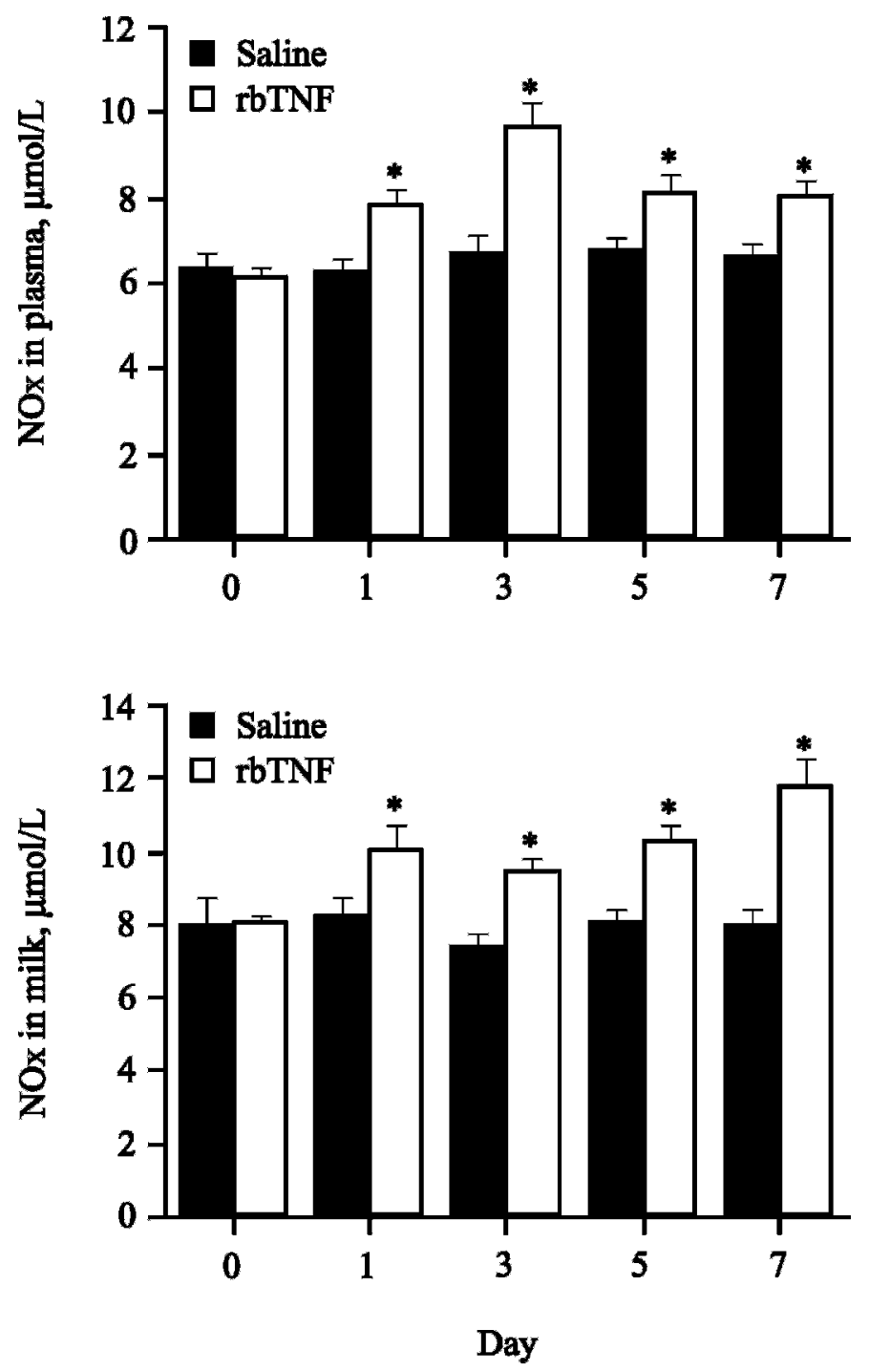

Figure 6. Concentrations of nitrite plus nitrate $(\mathrm{NOx})$ in plasma (upper panel) and milk (lower panel) of cows treated with saline (control, $3 \mathrm{~mL} / \mathrm{head})$ or $\mathrm{rbTNF}(2.5 \mu \mathrm{g} / \mathrm{kg})$ for $7 \mathrm{~d}(\mathrm{~d} 0-6)$. See Figure 1 for key.

Thyroid hormones are also important for maintaining lactation, and stimulate the basic metabolic rate via enhancing the metabolism of carbohydrates, lipids, and proteins (Nixon et al., 1988). $\mathrm{T}_{3}$ is the most metabolically active thyroid hormone (Refsal et al., 1984). The concentration of plasma $\mathrm{T}_{3}$ was related positively with the basic metabolic rate of lactating cows (Refsal et al., 1984). On the other hand, TNF inhibits the synthesis and secretion of $\mathrm{T}_{3}$ and mediates alterations in thyroid hormone metabolism in rats (Pang et al., 1989). In our study, rbTNF treatment induced a decrease of the plasma $\mathrm{T}_{3}$ concentration compared with that in the control cows, suggesting suppression of the basic metabolic

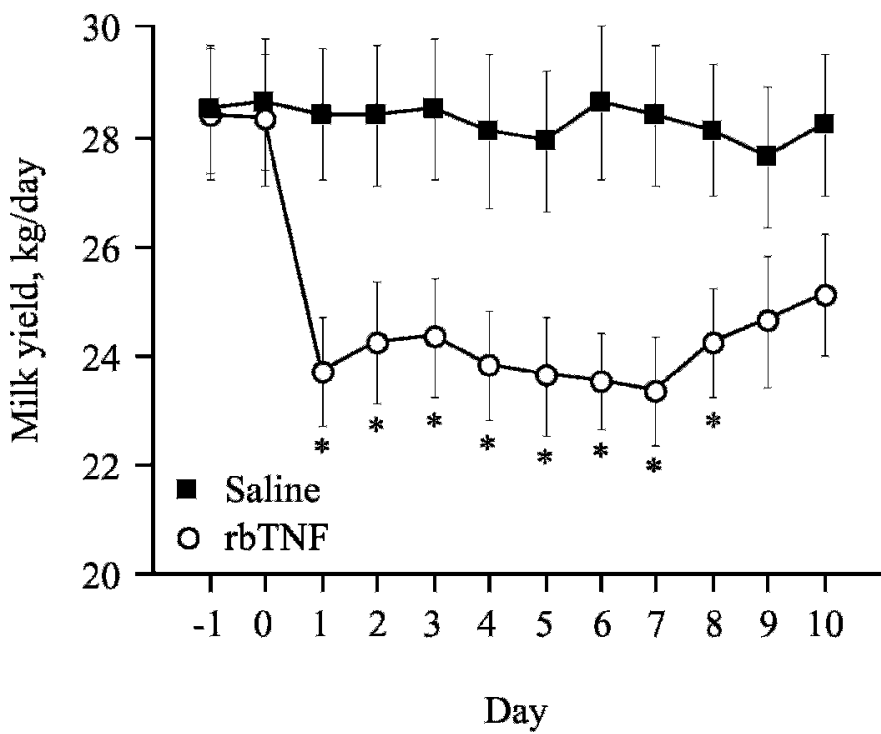

Figure 7. Milk yield of cows treated with saline (control, $3 \mathrm{~mL} /$ head) or $\operatorname{rbTNF}(2.5 \mu \mathrm{g} / \mathrm{kg})$ during the pre-treatment $(\mathrm{d}-1)$, treatment $(\mathrm{d} 0-6)$, and posttreatment $(\mathrm{d} 7-10)$ periods. The saline or rbTNF was administered at $1200 \mathrm{~h}$ daily for $7 \mathrm{~d}(\mathrm{~d} 0-6)$. Values are means for 12 cows with SE represented by vertical bars. $* P<0.05$ compared with control.

rate and the synthesis and secretion of $\mathrm{T}_{3}$ by rbTNF in the lactating cows.

In the present study, the basal concentration of ST in plasma was increased by rbTNF administration. In contrast, daily rbTNF treatment induced a decrease in the plasma concentration of IGF-1 in the lactating cows. These findings are in agreement with previous reports that investigated the effect of negative energy balance, restricted feed or mastitis on the plasma ST and IGF1 concentrations in lactating cows (Burvenich et al., 1999; Gluckman et al., 1987). Furthermore, a recent study suggested that i.v. administration of endotoxin decreases the plasma concentration of IGF-1 in steers, and that the effect is not totally explained by the changes in voluntary feed intake that accompany endotoxin administration (Elsasser et al., 1995). In rats, TNF inhibited the expression of the IGF-1 and IGF-1 receptor genes in liver, in association with a reduction in the concentration of IGF-1 in the plasma (Char et al., 1995). On the other hand, the plasma ST response to exogenous STRH was lower in the rbTNF-treated cows than in the control cows. This result is in agreement with the results obtained in our previous studies using heifers (Kushibiki et al., 2000b) and steers (Kushibiki et al., 2001). A recent study indicated that TNF receptors are found in the bovine pituitary gland (Elsasser et al., 1991). In addition, TNF inhibits STRHstimulated ST release in cultured bovine pituitary cells (Elsasser et al., 1991). 

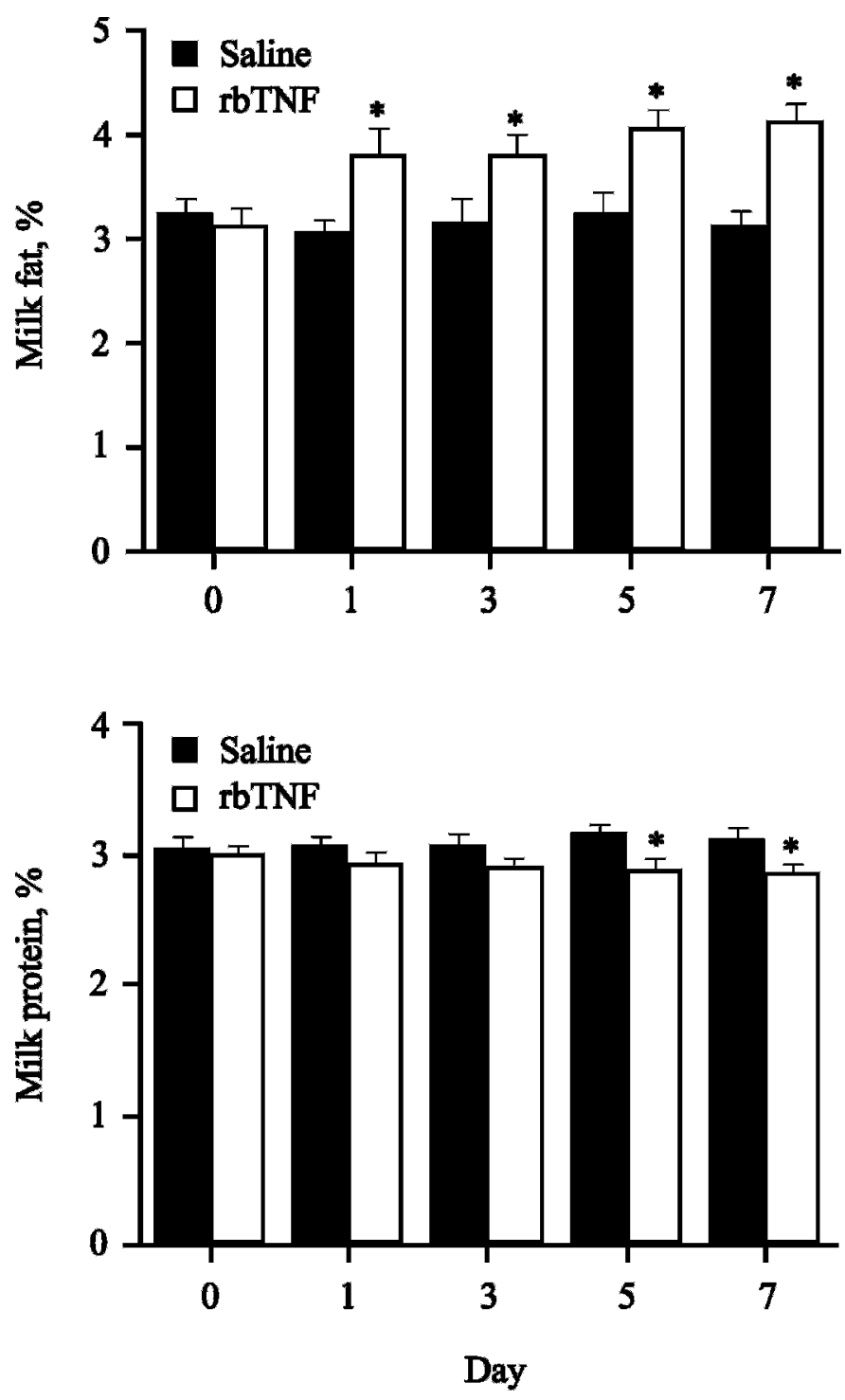

Figure 8. Percentages of fat (upper panel) and protein (lower panel) in milk of cows treated with saline (control, $3 \mathrm{~mL} / \mathrm{head}$ ) or $\operatorname{rbTNF}(2.5 \mu \mathrm{g} / \mathrm{kg})$ for $7 \mathrm{~d}(0-6 \mathrm{~d})$. Values are means for 12 cows with SE represented by vertical bars. ${ }^{*} P<0.05$ compared with control.

NO acts as a mediator of many of the pathological consequences of endotoxin or infection, and is generated in response to various cytokines, especially TNF (Cunha et al., 1994). In vivo studies using lactating cows have suggested that NO has important metabolic and endocrine effects (Blum et al., 2000; Hirvonen et al., 1999). The plasma $\mathrm{NO}_{\mathrm{x}}$ concentration was also increased by intramammary challenge with $E$. coli (Blum et al., 2000; Hoeben et al., 2000). These observations may indicate that there is a close relationship between TNF and NO production during coliform mastitis in lactating cows (Blum et al., 2000; Hoeben et al., 2000). Our data provide the first evidence that exogenous
rbTNF treatment elevated $\mathrm{NO}_{\mathrm{x}}$ production in the plasma and milk of lactating cows.

In studies using the mastitis model to investigate the pathophysiological causes of reduced lactational performance during mastitis, milk yields in early lactation were depressed in quarters not receiving $E$. coli despite the absence of inflammation in these quarters (Heyneman et al., 1990; Hoeben et al., 2000). In contrast, milk production in early lactation decreased rapidly, but was less pronounced, after intramammary infusion of endotoxin (Hoeben et al., 2000). The milk production losses in the untreated quarters were negligible in endotoxin mastitis (Hoeben et al., 2000). Thus, the suppression of milk production was apparently mediated in part by systemic effects of intramammary $E$. coli infusion, and may be caused by changes in the concentrations of stimulatory or inhibitory hormones (e.g., ST, $\mathrm{T}_{3}$, and cortisol) (Hoeben et al., 2000; Lohuis et al., 1988b; Shuster et al., 1991c). The stage in lactation is an important epidemiologic factor of the relationship between milk production loss and mastitis (Bartett and Van Wijk, 1991). Several studies have reported on the differences in the milk production patterns following clinical mastitis between the stage of early and middle to late lactation (Lescourret and Coulon, 1994; Lucey and Rowlands, 1984). Most cases of acute or peracute coliform mastitis occur from calving to peak lactation (Lohuis et al., 1990). Data from the present study indicated that rbTNF induced systemic responses associated with mastitis in peak lactation, including a decrease in milk production, an increase of fat content and a decrease of protein content in milk. These changes in milk composition were similar to those observed following i.v. endotoxin treatment (Shuster et al., 1991b). Also, there was a significant increase in fat concentration in milk from the uninfected quarters after intramammary injection of $E$. coli (Massart-Leen et al., 1994). It is likely that the increased milk fat percentage was mediated by the rbTNF-induced catabolic state of the host (e.g., hepatic lipogenesis and decreased adipose tissue mass) and the suppression of milk production. On the other hand, an in vitro study showed that TNF inhibited the secretion of casein from bovine mammary cells (Hurley et al., 1994). Watanabe et al. (2000) demonstrated in vivo that the concentrations of casein, $\beta$-lactoglobulin, and $\alpha$-lactalbumin in milk were significantly decreased following intramammary rbTNF infusion.

In conclusion, this study showed that exogenous rbTNF injection induced many of the systemic responses associated with coliform mastitis in the plasma and milk of lactating cows. These findings support and confirm the hypothesis (Dosogne et al., 2002; Hoeben et al., 2000) that TNF, rather than LPS, is absorbed from the mammary gland and released into the circula- 
tion, and that TNF is responsible for the systemic changes observed during coliform mastitis.

\section{ACKNOWLEDGMENTS}

This study was supported by a Grant-in-Aid from the Recombinant Cytokine Project of the Ministry of Agriculture, Forestry and Fisheries, Japan (RCP 2000 4330). The authors thank Dr. S. Ohashi (National Institute of Advanced Industrial Science and Technology) for providing the STRH. We also wish to thank Mr. K. Mitani (National Institute of Animal Health) and Mr. T. Narita (National Institute of Livestock and Grassland Science) for assistance with analysis of milk composition.

\section{REFERENCES}

Alsemgeest, S. P. M., H. C. Kalsbeek, T. C. Wensing, J. P. Koeman, A. M. van Edern, and E. Gruys. 1994. Concentrations of serum SAA and HP parameters of inflamammatory disease in cattle. Vet. Quart. 16:21-23.

Bartlett, P. C., and J. Van Wijk. 1991. Temporal patterns of lost milk production following clinical mastitis in a large Michigan Holstein herd. J. Dairy Sci. 74:1561-1572.

Baumann, H., and J. Gauldie. 1994. The acute phase response. Immunol. Today. 15:74-80.

Bernardini, R., T. C. Kamilaris, A. E. Calogero, E. O. Johnson, M. T. Gomez, P. W. Gold, and G. P. Chrousos. 1990. Interactions between TNF-alpha, hypothalamic corticotropin-releasing hormone, and adrenocorticotropin secretion in the rat. Endocrinol. 126:2876-2881.

Blum, J. W., R. M. H. Dosogne, D. Hoeben, F. Vangroenweghe, R. W. Bruckmaier, H. M. Hammon, and C. Burvenich. 2000. TNF and nitrite/nitrate responses during acute mastitis induced by Escherichia coli infection and endotoxin in dairy cows. Domestic Animal Endocrinol. 19:223-235.

Burvenich, C., M. J. Paape, D. Hoeben, H. Dosogne, A. M. MassartLeen, and J. Blum. 1999. Modulation of the inflammatory reaction and neutrophil defense of the bovine lactating mammary gland by growth hormone. Domest. Anim. Endocrinol. 17:149-159.

Cunha, F. Q., J. Assreuy, D. W. Moss, D. Rees, L. M. C. Leal, S. Moncada, M. Carrier, C. A. O’Donnell, and F.Y. Liew. 1994. Differential induction of nitric oxide synthase in various organs of the mouse during endotoxaemia: Role of TNF-alpha and IL-1-beta. Immunology. 81:211-215.

Dosogne, H., E. Meyer, A. Sturk, J. van Loon, A. M. Massart-Leen, and C. Burvenich. 2002. Effect of enrofloxacin treatment on plasma endotoxin during bovine Escherichia coli mastitis. Inflamm. Res. 51:201-205.

Elsasser, T. H., T. J. Caperna, and R. Fayer. 1991. TNF-alpha affects GH secretion by a direct pituitary interaction. Proc. Soc. Exp. Biol. Med. 198:547-554.

Elsasser, T. H., T. J. Capera, and T. S. Rumsey. 1995. Endotoxin administration decreases plasma IGF-1 and IGF-binding protein2 in Angus $\times$ Hereford steers independent of changes in nutritional intake. J. Endocrinol. 144:109-117.

Feingold, K. R., and C. Grunfeld. 1987. TNF-alpha stimulates hepatic lipogenesis in the rat in vivo. J. Clin. Invest. 80:184-190.

Gluckman, P. D., B. H. Breier, and S. R. Davis. 1987. Physiology of the somatotropic axis with particular reference of the ruminant. J. Dairy Sci. 70:442-446.

Green, A., S. B. Dobias, D. J. A. Walters, and A. R. Brasier. 1994. TNF increases the rate of lipolysis in primary cultures of adipocytes without altering levels of hormone-sensitive lipase. Endocrinology. 134:2581-2588.
Consortium. 1988. Guide for the Care and Use of Agricultural Animals in Agricultural Research and Teaching. Assoc. Headquarters, Savoy, IL.

TNAES. 1998. Guide for the Care and Use of Agricultural Animals in Agricultural Research of the National Agricultural Research Center for Tohoku Region. Tohoku. Natl. Agric. Exp. Stn., Morioka, Japan.

Heyneman, R., C. Burvenich, and R. Vercauteren. 1990. Interaction between the respiratory burst activity of neutrophil leukocytes and experimentally induced Escherichia coli mastitis in cows. J. Dairy Sci. 73:985-994.

Hill, A. W., A. L. Shears, and K. G. Hibitt. 1979. The pathogenesis of experimental Escherichia coli mastitis in newly calved dairy cows. Res. Vet. Sci. 26:97-101.

Hirvonen, J., K. Eklund, A. M. Teppo, G. Huszenicza, M. Kulcsar, H. Saloniemi, and S. Pyorala. 1999. Acute phase response in dairy cows with experimentally induced Escherichia coli mastitis. Acta. Vet. Scand. 40:35-46.

Hodate, K., T. Johke, A. Ozawa, and S. Ohashi. 1990. Plasma growth hormone, insulin-like growth factor-1, and milk production responses to exogenous human growth hormone-releasing factor analogs in dairy cows. Endocrinol. Jpn. 37:261-273.

Hoeben, D., C. Burvenich, E. Trevisi, G. Bertoni, J. Hamann, R. M. Bruckmaier, and J. W. Blum. 2000. Role of endotoxin and TNF in the pathogenesis of experimentally induced coliform mastitis in periparturient cows. J. Dairy Res. 67:503-514.

Hurley, W. L., M. Aslam, M. Hegarty, and A. Morkoc. 1994. Synthesis of lactoferrin and casein by explants of bovine mammary tissue. Cell. Biol. Int. 18:629-637.

Jackson, J. A., D. E. Shuster, W. J. Silvia, and R. J. Harmon. 1990. Physiological responses to intramammary or intravenous treatment with endotoxin in lactating dairy cows. J. Dairy Sci. 73:627-632.

Japanese Feeding Standard for Dairy Cattle. 1994. Agricultural, Forestry and Fisheries Research Council Secretariat, MAFF. 2nd ed. Central Association of Livestock Industry, Tokyo.

Johke, T. 1978. Effects of TRH on circuling growth hormones, prolactin and triiodothyronine levels in the bovine. Endocrinol. J. 25:19-26.

Kent, J. 1992. Acute-phase proteins in veterinary diagnosis. Br. Vet. J. 148:279-281.

Kushibiki, S., K. Hodate, H. Sgingu, Y. Okabe, A. Watanabe, Y. Mori, T. Itoh, and Y. Yokomizo. 2000a. Acute phase responses and metabolic and hormonal changes induced by rbTNF-alpha in calves. Bull. Tohoku. Natl. Agric. Exp. Stn. 96:39-50.

Kushibiki, S., K. Hodate, Y. Ueda, H. Sgingu, Y. Mori, T. Itoh, Y. Yokomizo, 2000b. Administration of rbTNF- $\alpha$ Affects intermediary metabolism and insulin and growth hormone secretion in Dairy heifers. J. Anim. Sci. 78:2164-2171.

Kushibiki, S., K. Hodate, Y. Ueda, H. Sgingu, Y. Mori, T. Itoh, and Y. Yokomizo. 2001. Effect of long-term administration of rbTNF on glucose metabolism and hormone secretion in Holstein steers. Am. J. Vet. Res. 62:794-798.

Lescourret, F., and J. B. Coulon. 1994. Modeling the impact of mastitis on milk production by dairy cows. J. Dairy Sci. 77:2289-2301.

Lohuis, J. A. C. M., J. H. M. Verheijden, C. Burvenich C, and A. S. J. P. M. van Miert. 1988a. Pathophysiological effects of endotoxin in ruminants. 1. Changes in body temperature and reticulo-rumen motility, and effect of repeated administration. Vet. Quart. 10:109-116.

Lohuis, J. A. C. M., J. H. M. Verheijden, C. Burvenich, and A. S. J. P. M. van Miert. 1988b, Pathophysiological effects of endotoxin in ruminants. 2. Metabolic. Vet. Quart. 10:117-125.

Lohuis, J. A. C. M., Y. H. Schukken, J. H. M. Verheijden, A. Brand, and A. S. J. P. M. van Miert. 1990. Effect of severity of systemic signs during the acute phase of experimentally induced Escherichia coli mastitis on milk production losses. J. Dairy Sci. 73:333-341.

Lohuis, J. A. C. M., H. M. Sutter, T. Graser, B. Ludwig, A. S. J. P. A. M. van Miert, W. F. Rehm, E. Rohde, B. Schneider, M. Wanner, and T. van Werven. 1992. Effects of endotoxin-induced mastitis 
on the pharmacokinetic properties of aditoprim in dairy cows. Am. J. Vet. Res. 53:2311-2314.

Lucey, S., and G. J. Rowlands. 1984. The association between clinical mastitis and milk yield in dairy cows. J. Dairy Res. 39:165-175.

Massart-Len, A. M., C. Burvenich, and D. L. Massart. 1994 Triacylglycerol fatty acid composition of milk from periparturient cows during acute Escherichia coli mastitis. J. Dairy Res. 61:191-199.

Mooradian, A. D., R. L. Reed, D. Osterweil, R. Schiffman, and P. Scuderi. 1990. Decreased serum triiodothyronine is associated with increased concentrations of tumor necrosis factor. J. Clin. Endocrinol. Metab. 71:1239-1242.

Morimatu, M., M. Saricaputi, B. Syuto, M. Saito, S. Yamamoto, and M. Nakai. 1992. Bovine haptoglobin, single radial immunodiffusion assay of its polymeric forms and dramatic rise in acute-phase sera. Vet. Immunol. Immunopathol. 33:356-372.

Nixon, D. A., M. A. Akasha, and R. R. Anderson. 1988. Free and total thyroid hormones in serum of Holstein cows. J. Dairy Sci. $71: 1152-1160$.

Peel, C. J., and D. E. Bauman. 1987. Somatotropin and lactation. J. Dairy Sci. 70:474-486.

Pang, X. P., J. M. Hershman, C. J. Mirell, and A. E. Pekary. 1989. Impairment of hypothalamic-pituitary-thyroid function in rats treated with human recombinant tumor necrosis factor- $\alpha$ (cachectin). Endocrinol. 125:76-83.

Pighetti, G. M., and L. M. Sordillo. 1994. Regulation of mammary gland macrophage TNF production with IFN-gamma. Res. Vet. Sci. 56:252-255.
Refsal, K. R., R. F. Nachreiner, and C. R. Anderson. 1984. Relationship of season, herd, lactation, age, and pregnancy with serum thyroxine and triiodothyronine in Holstein cows. Domest. Anim. Endocrinol. 1:225-232.

Rumsey, T. S., S. Kahl, S. A. Norton, J. Eisemann, T. H. Elsasser, A. C. Hammond, H. F. Tyrrell, and J. Bitman, 1990. Evidence that bovine growth hormone treatment increases the rate of extrathyroidal 5'-monodeiodinase activity in cattle. Domest. Anim. Endocrinol. 7:125-133.

SAS User's guide: Statistics, Version 6.03 Edition, 1988. SAS Inst. Inc., Cary, NC.

Shuster, D. E., R. J. Harmon, J. A. Jackson, and R. W. Hemken, 1991a. Endotoxin mastitis in cows milked four times daily. J. Dairy Sci. 74:1527-1538.

Shuster, D. E., R. J. Harmon, J. A. Jackson, and R. W. Hemken. 1991b. Reduced lactational performance following intravenous endotoxin administration to dairy cows. J. Dairy Sci. 74:34073411.

Shuster, D. E., R. J. Harmon, J. A. Jackson, and R. W. Hemken. 1991c. Suppression of milk production during endotoxin-induced mastitis. J. Dairy Sci. 74:3763-3774.

Watanabe, A., Y. Yagi, H. Shiono, Y. Yokomizo. 2000. Effect of intramammary infusion of TNF on milk composition and induction of acute-phase protein in the lactating cow. J. Vet. Med. B47:653-662. 